\title{
MEIO AMBIENTE: UM DIREITO FUNDAMENTAL DE SEGUNDA CATEGORIA
}

\author{
José Adércio Leite Sampaio ${ }^{1}$ \\ Escola Superior Dom Helder Câmara (ESDHC)
}

Elcio Nacur Rezende ${ }^{2}$

Escola Superior Dom Helder Câmara (ESDHC)

\section{RESUMO}

No Brasil, o direito ao meio ambiente ecologicamente equilibrado é um direito fundamental. Seu reconhecimento se tem dado à base de considerações formais e dogmáticas. A falta de elementos conceituais e justificantes mais aprofundados talvez explique um tratamento legislativo e judicial pouco deferente a esse direito. Na prática, o Direito Ambiental ainda é tratado como se fosse um capítulo do Direito Administrativo ou um Direito Administrativo Especial, e o direito ao meio ambiente ecologicamente equilibrado, como um direito fundamental de segunda classe. Este texto objetiva explanar esse tratamento jurídico, apontando seus multifacetados aspectos, concluindo pela necessidade de se conferir ao meio ambiente maior proteação. Foi utilizada a metodologia hipotética dedutiva, concluindo-se pela necessidade da elaboração de uma doutrina e jurisprudência que seja capaz de conferir uma efetiva proteção ambiental.

Palavras-chave: direito fundamental; direito fundamental ao meio ambiente ecologicamente equilibrado; Supremo Tribunal Federal.

1 Pós-Doutor, Doutor e Mestre em Direito. Professor da Escola Superior Dom Helder Câmara. Procurador da República. ORCID: https://orcid.org/0000-0002-9452-4811 / e-mail: joseadercio. contato@gmail.com

2 Pós-Doutor, Doutor e Mestre em Direito. Professor da Escola Superior Dom Helder Câmara. Procurador da Fazenda Nacional. ORCID: https://orcid.org/0000-0002-2369-8945 / e-mail: elcionrezende@yahoo.com.br 


\section{ENVIRONMENT: A SECOND-RATE FUNDAMENTAL RIGHT}

\section{ABSTRACT}

In Brazil, the right to an ecologically balanced environment is a fundamental right. Its recognition has been based on formal and dogmatic considerations. The lack of more in-depth conceptual and justifying elements may explain the legislative and judicial treatment that has little respect for this right. In practice, Environmental Law is still treated as if it were a chapter of Administrative Law or a Special Administrative Law; and the right to an ecologically balanced environment, as a fundamental second-class right. This text aims to explain this legal treatment, pointing out its multifaceted aspects. The hypothetical deductive methodology was used, concluding that there is a need to develop a doctrine and jurisprudence that is capable of providing effective environmental protection.

Keywords: Federal Court of Justice; fundamental right; fundamental right to an ecologically balanced environment. 


\section{INTRODUÇÃO}

O direito ao meio ambiente ecologicamente equilibrado é considerado no Brasil um direito fundamental. Como se verá, o Supremo Tribunal Federal o afirmará em diversas oportunidades. Todavia, pouco se tem debatido acerca dessa fundamentalidade.

Nesse quadro, apresenta-se como problemática deste estudo a indagação: o que faz de um direito ou uma pretensão, fundamental? Depois, quais as consequências jurídicas e políticas que advêm dessa consideração? Esse é um debate que precisa ser enfrentado pela literatura constitucional e ambiental no País.

O tema central é, portanto, a pesquisa sobre o acolhimento da fundamentalidade de um direito a partir apenas de sua consideração dogmática pode enfraquecê-lo, quando for desafiado por outras pretensões ou interesses. Os juízos de adequação legislativa e de aplicação judicial costumam ser-lhe menos exigente, dando maior proteção prática aos seus desafiadores, especialmente quando se trata de interesses econômicos.

Justifica-se o presente texto, a partir da afirmação de que tal tese precisa de confirmação e que se espera seja dada no presente artigo.

Objetiva-se, por isso, fazer uma revisão bibliográfica e um apelo à jurisprudência, nomeadamente do Supremo Tribunal Federal, para analisar se o direito ao meio ambiente ecologicamente equilibrado (DMAEE) é efetivamente tratado como tal, um direito fundamental.

\section{O DIREITO AO MEIO AMBIENTE ECOLOGICAMENTE EQUILIBRADO COMO UM DIREITO FUNDAMENTAL}

A definição de um direito fundamental não é das mais simples. É preciso que se reúnam elementos formais e materiais, jurídicos e sociológicos, políticos e históricos para sua formulação. No Direito, costuma-se valer apenas de seu aspecto formal: fundamental é aquilo que a Constituição diz que é. Mas o entendimento do que a Constituição "diz" ser é em si problemático. A Constituição brasileira, por exemplo, dedica o Título II aos "Direitos e Garantias Fundamentais". Estariam sob esse Título todos os direitos fundamentais, por ela, reconhecidos? Qualquer iniciante nos estudos de Direito Constitucional responderá negativamente, baseado, na linha do pensamento dogmático e na jurisprudência do Supremo Tribunal Federal. O Tribunal já reconheceu que alguns direitos dos contribuintes, 
presentes - ainda que na forma de garantias institucionais - no art. 150 da Constituição, integram o patrimônio da jusfundamentalidade (BRASIL, 2014a; 2014b).

Nenhum repertório será exaustivo nem estático, em virtude da possibilidade sempre posta no horizonte de construção hermenêutica da Corte. Ao que interessa na apresentação do direito ao meio ambiente ecologicamente equilibrado, essa dimensão formal foi cumprida. Embora tenha sido afirmado no art. 226 da Constituição, a léguas jurídicas de distância normativa daquele Título II, o Supremo Tribunal Federal já o reconheceu como fundamental. Quem não se lembrará do profundo voto do ministro Celso de Mello que, de modo emblemático, inseriu o direito ao meio ambiente ecologicamente equilibrado no rol de jusfundamentalidade. A ementa é um neon conceitual:

Todos têm direito ao meio ambiente ecologicamente equilibrado. Trata-se de um típico
direito de terceira geração (ou de novíssima dimensão), que assiste a todo o gênero
humano (RTJ 158/205-206). Incumbe, ao Estado e à própria coletividade, a especial
obrigação de defender e preservar, em benefício das presentes e futuras gerações,
esse direito de titularidade coletiva e de caráter transindividual (RTJ 164/158-161). O
adimplemento desse encargo, que é irrenunciável, representa a garantia de que não se
instaurarão, no seio da coletividade, os graves conflitos intergeneracionais marcados
pelo desrespeito ao dever de solidariedade, que a todos se impõe, na proteção desse
bem essencial de uso comum das pessoas em geral (BRASIL, 2005).

Estava dita, além da fundamentalidade a dimensionalidade (geracional) do direito, sua transindividualidade e transgeracionalidade, sua raiz solidarista, seus promotores ou passivos sujeitos da relação jusfundamental (Estado e coletividade). Precisava ser dito mais alguma coisa para o Direito. Para alguns, não. O próprio STF teria assumido para si, com esse reconhecimento, uma tarefa de realização que haveria de realizar, sob pena de tutela insuficiente. É um tema que se discutirá em breve. O que resta a afirmar é que a afirmação de um direito como fundamental não se pode resumir à retórica ou apologética de sua classe. Ele deve ser tratado como tal e se devem buscar elementos materiais que embasem sua qualidade.

A construção do argumento de fundamentalidade pelo Supremo Tribunal Federal valeu-se da sistematicidade constitucional que perpassa as frestas do parágrafo segundo do art. $5^{\circ}$ (dimensão jurídica). Mas ela foi resultado de uma confluência de elementos materiais que a embasara: a interpelação da circunstância histórica e factual (sua dimensão sociológica ou empírica) e o apoio em quase sempre ousadas ou ao menos inovadoras 
literaturas (dimensão epistêmica), que refletem o resultado de lutas e conflitos sociais nem sempre visíveis (ou expressos) nesse "processo de revelação" (dimensão política).

Aliás, esse é o processo típico de afirmação dos direitos "in fieri". Eles podem tanto já estar presentes na forma de reivindicações ainda não suficientemente amadurecidas em qualquer das quatro dimensões de positivação jusfundamental ou, mais especificamente, do "direito judicial jusfundamental"; como ainda viverem num futuro que mais ou menos se avizinha. Não haverá desaviso, se em breve se estiver falando e reivindicando um direito fundamental robótico ou clônico (MEHLMAN, 2012; ROBERTSON, 2014; GUNKEL, 2018). A ficção é forma tanto de simular quanto de antecipar situações virtuosas ou problemáticas da existência individual e social da humanidade.

As lutas e conflitos, os existentes e em devir, são traduzidos em argumentos jurídicos materiais de justificação de um direito fundamental (SAMPAIO, 2004; DUSSEL, 2015). As massivas intervenções humanas no ambiente levaram a um quadro tóxico de periclitação à saúde e à vida, com sérios reflexos à igualdade, denunciados pelos anseios de justiça ambiental, mobilizando energia de organização da sociedade e de lutas jurídicas e sociais, políticas e, por vezes, físicas que exigiram um arbitramento político e constitucional, dada a proporção a que chegaram. Como não se pode admitir que seja dado um salto lógico entre a concretude do real (das reivindicações que afloraram dos conflitos) e a abstração generalizante da norma, costuma-se buscar norma de inferência, lógica ou paralógica, que fundamente o juízo de afirmação. A literatura inovadora e ousada serve em grande escala para definir essa inferência.

O apelo tautológico é mais comum no caso do DFMAEE: o meio ambiente ecologicamente equilibrado é um direito fundamental, dada sua importância ou indispensabilidade para a sadia qualidade da vida, preferencialmente, humana (RENEDO, 2002). Ele é fundamental, porque é importante, é indispensável, é fundamental. Esses adjetivos costumam vir com justificativas que reportam à vida ou à saúde, embora, mais recentemente, não faltem apelos a justificações pós-humanistas, de uma difusa titularidade por animais não humanos ou mesmo da Gaia ou da Pachamama. Costura-se, assim, o elemento material ao direito.

Os argumentos materiais se aliam ao componente formal (e vice-versa) para equipar uma dada situação, qualidade ou posição jurídica de uma retórica - quase apologética - de um direito fundamental. Nem sempre, 
porém, extraindo-se daí as consequências jurídicas adequadas. Faltam-lhe atributos jurídico-constitucionais que a tornam distinguíveis dentro do arsenal de conceitos e direitos: servir de escudo contra incursões majoritárias que amesquinhem ou ponham em risco minorias. A velha - nem por isso desgastada - fórmula dworkiana de "trunfos" dos indivíduos ou da minoria (DWORKIN, 1977; TRIBE; DORF, 2007). Essa resistência existencial - e do mundo empírico - se transporta na linguagem deôntica de uma posição jurídica de resistência a intervenções legislativas que promovam aquele amesquinhamento ou risco. A "liberdade de configuração do legislador" é, na verdade, uma vinculação a um dever de tutela que suficientemente assegure a convivência de outros interesses constitucionais conflitantes aos das minorias sem que as ponham em risco nem lhes amesquinhem. Pôr em risco é desafiar sua integridade física ou moral, sincrônica e diacronicamente. Amesquinhar é deixar de tratar-lhes - e às suas pretensões - com o devido respeito e consideração. Esse é um problema sério na delimitação do DFAEE.

\section{O DIREITO FUNDAMENTAL AO MEIO AMBIENTE ECOLOGICAMENTE EQUILIBRADO LEVADO A SÉRIO - DEVERES EMPÍRICOS DAS INTERVENÇÕES LEGISLATIVAS E DOS CONTROLES JUDICIAIS}

O direito fundamental ao meio ambiente ecologicamente equilibrado tem suas particularidades que vão além de um índice elevado de indeterminação semântica e de uma necessidade de conhecimentos que estão fora do Direito. Mais do que em qualquer outro domínio jurídico, as "ciências auxiliares" aqui são determinantes na atribuição de sentidos aos institutos e na formulação de políticas públicas de promoção jusfundamental (CARREÑO, 2019). É um aspecto que quase sempre passa despercebido ou não recebe a devida atenção. As particularidades, como se disse, estão também dentro do Direito.

A natureza dos bens jurídicos tutelados e a necessidade de sua proteção eficaz justificam o desenvolvimento de princípios como o poluidor-pagador e a precaução ${ }^{3}$. Ambos, bem ou mal, reconhecidos pelo Supremo

3 O STF já reconheceu a precaução como princípio do direito ambiental. Sua aplicação é, todavia, problemática. A própria decisão em comento parece se contradizer ao mencionar que a incerteza exige silêncio das Cortes: "A capacidade institucional, ausente em um cenário de incerteza, impõe autocontenção do Judiciário, que não pode substituir as escolhas dos demais órgãos do Estado por suas próprias escolhas". (ADC 42. Item 18 da Ementa). Num tempo é que a incerteza é novo normal, a adoção dessa doutrina pode significar a negativa de jurisdição, notadamente no campo ambiental. 
Tribunal Federal, importam outro: a inversão do ônus da prova ${ }^{4}$. Cabe ao proponente de intervir no ambiente provar que não ocorrerão danos além dos aceitáveis no "trade-off" de custos e benefícios, assim como ao que está respondendo por danos ambientais demonstrar que não os causou ou o fez em menor escala.

Esse princípio, ainda restrito ao processo, há de ser aplicado também às políticas públicas que resultem em maior intervenção ecológica: cabe a seus formuladores demonstrarem, com suportes fáticos e prognoses verossímeis, que não haverá comprometimento sério à integridade ecossistêmica ou, se houver, que houve um juízo de adequado sopesamento entre interesses preservacionistas e os benefícios gerados com a nova política, a ponto de justificar o "trade-off" ambiental". A presunção de constitucionalidade de uma lei ou ato administrativo não pode desconsiderar essa inversão.

Ao contrário, deve contemplá-la. Só há presunção se houver elementos bastantes de correção da prognose. O próprio Supremo Tribunal, valendo-se de entendimento de seu par estadunidense, afastou a possibilidade de escrutínio empírico da escolha do legislador que se pode fundar em "especulações racionais não embasadas em provas ou dados empíricos". Alterações legislativas supostamente mais gravosas ao meio ambiente devem estar ancoradas em evidências empíricas que permitam ao intérprete identificar a justeza de seus prognósticos e a correção dos argumentos de justificação empregados.

Ao legislador é dado um amplo espaço na construção discursiva de consensos possíveis, segundo a normatividade de pretensões de certeza e correção moral e ética, e a faticidade de acordos equânimes de interesses, que, dentro de seu espaço de discricionariedade, deve estar imune ao

4 A matéria é pacífica no âmbito do Superior Tribunal de Justiça (Súmula 618). No STF, há reconhecimento em matéria de defesa do consumidor (Pleno. ARE-ED-AgR 1224559/PR. Rel. Min. Dias Toffoli, j. 11/11/2019). O assunto não foi enfrentado em recurso extraordinário por dispor sobre questão intraconstitucional (1a. Turma. AI-AgR 794553/RS. Rel. Min. Dias Toffoli, j. 18/06/2013).

5 Em domínios gerais, o controle é mais deferente, defendendo alguns a "não controlabilidade das prognoses legislativas" (CANOTILHO, 1991, p. 1123). Na Alemanha, a falta ou falha de prognósticos, $a b$ initio, pode levar à nulidade da lei. $\mathrm{O}$ erro de prognóstico, verificável apenas a posteriori, não permite controle, desde que tenha sido feito no âmbito de um processo legislativo regular (MENDES, 2000). Sobre a necessidade de realização de uma prognose legislativa, balizada, inclusive, em dados empíricos, como exige expressamente o art. 170 da Constituição suíça (SCALCON, 2017; BICKENBACH, 2016).

6 No item 17 da ementa à ADC 42 se lê: “ A Jurisdição Constitucional encontra óbice nos limites da capacidade institucional dos seus juízes, notadamente no âmbito das políticas públicas, cabendo ao Judiciário a análise racional do escrutínio do legislador, consoante se colhe do julgado da Suprema Corte Americana FCC v. Beach Communications, Inc. 508 U.S. 307 (1993), em que se consignou que 'a escolha do legislador não está sujeita ao escrutínio empírico dos Tribunais e pode se basear em especulações racionais não embasadas em provas ou dados empíricos' ('Legislative choice is not subject to courtroom factfinding and may be based on rational speculation unsupported by evidence or empirical data')". 
escrutínio judicial (HABERMAS, 2005). Não quer isso dizer que esteja inteiramente livre de controle de seus prognósticos. As cortes, aliás, vão e vêm nessa doutrina de insindicabilidade. O próprio juízo de ponderação, tão caro ao Supremo Tribunal Federal, é uma forma de perscrutação dos motivos instrumentais da opção legislativa. A franquia tem limite.

\section{O DIREITO FUNDAMENTAL AO MEIO AMBIENTE ECOLOGICAMENTE EQUILIBRADO (POUCO) LEVADO A SÉRIO - DEVERES EMPÍRICOS DAS INTERVENÇÕES LEGISLATIVAS E DOS CONTROLES JUDICIAIS DESCUMPRIDOS}

A linguagem constitucional é vezeira em dar nomes aos supostos testes de resolução dos conflitos entre interesses constitucionalmente protegidos. Razoabilidade, proporcionalidade, ponderação, sopesamento e concordância prática são algumas denominações, ora diferenciais, por matriz teórica ou relacional; ora equivalentemente empregadas, por erro ou deliberação, para resolver conflitos constitucionais. Não passam de operações semântico-sintáticas que se balizam pela coerência e coesão argumentativa, mais do que por seu aspecto pragmático, embora, seja esse, no fundo, o mais decisivo. $\mathrm{O}$ "pragma" da linguagem aqui se refere tanto à consideração dos efeitos da operação, denunciada, nalguns fóruns, como consequencialista e invasiva dos domínios políticos; quanto pelas motivações profundas da decisão, relegadas a estudos das ciências sociais e à historiografia dos jogos de linguagem do sistema de dominação (TANFORD, 1990; STINSON, 1997; NORTON, 2006; GIBSON, 2008; RACHLINKSKI, 2010)7.

O juiz é um "ser-no-mundo", submetido às contingências de seu tempo e aos seus preconceitos. Não é um autômato, máquina ou robô. Sua imparcialidade é sempre uma parcialidade refreada por um sentido deontológico de correção, mas é incapaz de subtraí-lo dos embates valorativos, especialmente, em domínios de interação entre demandas de (sub)sistemas sociais que lhe (im)pressionam ${ }^{8}$. A cultura do Antropoceno, por exemplo, o embebe e às suas decisões, podendo tornar razoáveis e proporcionais muitas intervenções legislativas que traduzem valores econômicos sobrepostos a interesses ambientais, cuja prevalência, em outros domínios, por exemplo, na venda de órgãos humanos ou na celebração de contratos de

7 Não é diferente em outros processos decisórios (HASTIE; DAWES, 2009).

8 Vejam-se as indicações na nota anterior e, especialmente: Prado (2003), Ribeiro (2006) e Gibson (2008). Ainda: Irwin e Real (2010), Neitz (2013) e Carvalho (2020). 
escravitude sexual, seria inteiramente refutada, por desarrazoada, desproporcional, absurda. Nesse sentido:

\footnotetext{
Percebe-se, portanto, que a crise socioambiental traz consigo uma nova dimensão de direitos fundamentais - chamada de terceira dimensão - a qual impõe ao Estado de Direito o desafio de inserir, entre suas tarefas prioritárias, a proteção do meio ambiente. Desvencilha-se de uma visão puramente antropocêntrica para o antropocentrismo alargado, que justifica um novo standard estatal, cujos fundamentos se desenvolvem sobre prescrições constitucionais, democráticas, sociais e ambientais (KALIL, FERREIRA; 2017, p. 329).
}

A própria equivalência aqui enunciada será, certamente, vista como despropositada. O domínio do econômico sobre o corpo, a sexualidade e a liberdade seguem uma gramática diferente daquela que lida com o ecológico. Nem sempre, porém, foi considerado desproporcional o instituto da escravidão - o sexo como acessório e franquia do principal. Nos debates em torno de uma eventual lei que abolisse a escravidão no Brasil, pesaram, durante muitos anos, argumentos que defendiam a propriedade e o direito adquirido contra a figura jurídica da escravidão (COSTA, 1997; 1999; GRINBERG, 1998-1999; SAMPAIO, 2004; MENDONÇA, 2008), atualmente atentatória ao sistema de direitos e à dignidade humana. Fossem os termos moda ao tempo, não seria difícil encontrar, na literatura da época, que tal intervenção no Estado nas relações privadas seria desarrazoada e desproporcional.

Embora seja negada a hierarquização entre direitos fundamentais, os exemplos acima dados, mostram que, na prática, ela existe. A tolerância à intervenção do legislador no âmbito normativo e de incidência do direito é seu melhor termômetro. Quanto mais tolerante, menos "fundamental". É o império do tempo, de suas contingências e valores; uma faticidade que desafia o sentido da normatividade.

O institucionalismo, sobretudo, de apelo democrático refuta essas notas: cabe ao legislador definir os espaços de proteção jusfundamental, atendendo ao mandamento de justa causa, do "devido" processo constitucional ou da proporcionalidade, por meio do escrutínio da ponderação, que há de respeitar, no limite, o conteúdo essencial do direito (HÄBERLE, 1997; SAMPAIO, 2013). Não haveria relação de prioridade entre direitos, portanto, mas uma tarefa de "harmonização de valores constitucionais".

Logo se poderia encontrar no conteúdo essencial do direito, como limite dos limites, seja no resíduo da proporcionalidade (em seu matiz

9 Outra forma de ver o problema é a partir do direito, interesse ou bem que justifica a limitação ou intervenção ao direito. Veja-se: Gervier (2014) e Sampaio (2015). 
relativo), seja na inexpugnável dignidade humana (em sua feição absoluta), o elemento de identificação do ponto vedado de ultrapassagem do legislador e equipará-lo à zona proibida de amesquinhamento ou risco sério à minoria, fazendo um amálgama - recorrente e tantas vezes equivocado - entre Dworkin e a Jurisprudência Constitucional alemã (SAMPAIO, 2013).

Mesmo essa mistura pode esconder a diferença de tratamento dispensado à "arbitragem" dos conflitos entre direitos. Uma rápida pesquisa na jurisprudência do Supremo Tribunal Federal mostra como há uma deferência maior ao legislador no estabelecimento das fronteiras do direito ao meio ambiente ecologicamente equilibrado, se comparado a outros direitos fundamentais ${ }^{10}$. A economia socava o núcleo de proteção ambiental com muito mais facilidade, constrangendo-lhe o que seria um conteúdo essencial. Aliás, essa é uma tendência na jurisprudência comparada. A Suprema Corte dos Estados Unidos, por exemplo, reluta em dar razão a argumentos em defesa do meio ambiente. A discricionariedade técnica e política se sobrepõe às teses preservacionistas com bastante frequência (FARBER, 1996; LAZARUS, 1999; PAUTZ, 2016). Mas há um crédito a ser dado ao par americano do Supremo Tribunal Federal: a proteção ambiental lá tem sede meramente legal.

Talvez a decisão mais emblemática que se possa trazer a exame seja aquela em que o STF examinou a constitucionalidade da Lei n. 12.651/2012, que instituiu o novo Código Florestal. Havia questionamentos sérios sobre os retrocessos trazidos pela nova legislação, que, esperava-se, o STF haveria de corrigir, afinal, tratava-se um direito fundamental de especial grandeza, sedo o ambiente "essencial" à sadia qualidade de vida das presentes e futuras gerações. Logo na ementa da decisão, um portal de frustração das expectativas: "a capacidade institucional, ausente em um cenário de incerteza, impõe autocontenção do Judiciário, que não pode substituir as escolhas dos demais órgãos do Estado por suas próprias escolhas" (BRASIL, 2018).

A deferência ao legislador era necessária, não apenas, pelas incertezas técnicas, que segundo o Tribunal, existiam em relação a uma série de assuntos em debate, mas também, a seu ver, em virtude da abertura do procedimento de elaboração da lei à sociedade. Enfatizou-se que mais de setenta audiências públicas foram realizadas, o que conferia maior transparência e adicional legitimidade às decisões legislativas, reforçando a "discricionariedade epistêmica e hermenêutica garantida ao Legislativo pela Constituição". Sob essas premissas, o argumento de atentado ao

10 Sobre a jurisprudência do Tribunal em matéria ambiental: Wedy (2008), Vilani (2009), Rocha (2013) e Gaio (2015). 
princípio [constitucional] da vedação do retrocesso não poderia sobreporse ao princípio democrático, nem justificar o afastamento de "arranjos legais mais eficientes para o desenvolvimento sustentável do país como um todo". Tampouco poderia ser aplicada a "tese de que a norma mais favorável ao meio ambiente deve[ria] sempre prevalecer", associada de maneira apressada, no julgamento, ao "in dubio pro natura", pois caberia ao agente "regulador distribuir os recursos escassos com vistas à satisfação de outros interesses legítimos" (BRASIL, 2018). Note-se quão caros são esses elementos de definição, verdadeiras "ferramentas conceituais" do direito fundamental.

O Tribunal parecia, no entanto, propenso a deixar na mão do Congresso a definição da política pública ambiental e, de arrasto, o conteúdo do direito fundamental pertinente, o que pareceria uma contradição com a definição de fundamentalidade de um direito. É certo que os ministros chegaram a declarar quatro dispositivos inconstitucionais e a outros seis deram interpretação conforme a Constituição. Por outro lado, declararam a constitucionalidade de trinta e três deles. O que chama a atenção é a delegação plena da competência de disposição de vários institutos ambientais aos legisladores, sem exigência de razões técnicas para justificar as escolhas feitas.

O reconhecimento de que o legislador poderia alterar a extensão das áreas de proteção permanente sequer atentara para o significado de tais áreas. Reduzir sua dimensão em 10 ou $50 \%$ causaria algum impacto nos fluxos gênicos ou migratórios? Promoveria maior ou menor assoreamento de rios e lagos? Por que motivo se alterou o marco para a medição da área de preservação ambiental ao longo de rios e cursos d'água, passando a ser o leito regular respectivo, e não mais seu nível mais alto? Que critério técnico se teria valido para admitir o cômputo das APPS no percentual da reserva legal? Aliás, qual a função ecológica da reserva legal que pudesse autorizar a lei a dispensar sua existência na exploração de potencial de energia hidráulica e construção ou ampliação de rodovias e ferrovias? Não bastaria estabelecer um juízo de aplicação formal de interesses contrapostos mais soberanos como a propriedade ou a prestação de serviços de energia elétrica, de atendimento do direito ao transporte e de integração das regiões do país.

Tais vetores de "policy" poderiam perfeitamente justificar a medida legislativa, mas a tanto era preciso se saberem os efeitos ecossistêmicos que teriam e, assim, realizar-se um sopesamento mais aprumado. Dá-se a impressão de que os institutos ambientais são "ornamentos biológicos" (e 
"retóricos") sem funções ecológicas e que estão à disposição do legislador como lhe aprouver. É bem interessante que, na discussão sobre a possibilidade de introdução de espécies exóticas para recomposição de reservas legais, preocupou-se com elementos empíricos e técnicos, ao dizer que inexistiam "provas científicas de que utilização de espécies exóticas para o reflorestamento de biomas sempre prejudica as espécies nativas ou causa desequilíbrio no habitat" (BRASIL, 2018). Valem, portanto, num caso; não interessam noutros. Numa autocontenção anticonsequencialista, validou, ainda, a anistia àqueles que causaram danos anteriores a 22 de agosto de 2008. No entender da Corte, cabe ao legislador "estabelecer uma espécie de marco zero na gestão ambiental do país", como se as normas até então em vigor não existissem. Sério? Em matéria ambiental? Nem se cogitou dos sinais que se emitiam à criação de expectativas de novos perdões como se, indiretamente, fosse criada uma licença a desmatar. O controle dos fatos legislativos ficou a dever, tão inconstante quanto discricionário.

\section{CONSIDERAÇÕES FINAIS}

O direito ao meio ambiente ecologicamente equilibrado é um direito fundamental. O Supremo Tribunal Federal já o afirmou diversas vezes. Essa é a justificativa formal ou dogmática da jusfundamentalidade. A ela se devem agregar aspectos sociológicos e empíricos, como os efeitos sociais, econômicos e ecossistêmicos da degradação ambiental; seus aspectos epistemológicos, sobretudo com sua defesa pela literatura especializada; e sua projeção política, a partir das lutas e conflitos sociais que geram as questões a ela (degradação) relacionadas.

Dada a imprecisão semântica do "meio ambiente ecologicamente equilibrado", o legislador e o juiz têm de recorrer aos domínios da técnica e da ciência para disciplinar de modo adequado seu conteúdo. Entretanto, para que seja respeitado o conteúdo essencial desse direito, é preciso que alguns princípios sejam considerados, especialmente porque, quase sempre, a tarefa de concretização envolve um "trade-off" com outros interesses, notadamente de expressão econômica.

Ao legislador é dado um amplo espaço na construção discursiva de consensos possíveis, segundo a normatividade de pretensões de certeza e correção moral e ética, e a faticidade de acordos equânimes de interesses, que estão dentro de seu espaço de discricionariedade. Não significa dizer que esteja inteiramente livre de controle das bases empíricas e dos prognósticos que empregou no exercício de sua tarefa. 
Cabe-lhe demonstrar à sindicância judicial que se utilizou de elementos técnicos adequados em seu exercício de ajustamento prático, não tendo sido a lei e a política que implementa mera roupagem legislativa da predominância a priori e incondicionada dos interesses contrapostos. Terá de provar que, segundo seu cálculo, não haverá comprometimento à integridade ecossistêmico-social ou, se houver, que este está devidamente justificado pelos benefícios gerados com a nova política legislativa adotada. A inversão do ônus da prova mitiga ou afasta a presunção de constitucionalidade de uma lei, sempre que ela afetar seriamente o ambiente ou importar um retrocesso ao quadro de proteção vigente. É uma decorrência da própria natureza do direito envolvido, do primado do "in dubio pro natura", do princípio da prevenção e do usuário ou poluidor-pagador. Chame-se-lhe de princípio do legislador-interventor.

A jurisprudência do Supremo Tribunal Federal, embora seja apologética à fundamentalidade do direito ao meio ambiente ecologicamente equilibrado, não lhe confere a proteção devida. O exame da constitucionalidade do Código Florestal revela bem isso. As incertezas sobre o grau de afetação do ambiente causado pela política legislativa adotada encontravam-se no espaço de sua livre apreciação, segundo a Corte. Se o juiz constitucional não sabe ou não se sente legitimado a lidar com incertezas, a proteção ambiental estará refém dos ajustes que fizer o Legislativo. Significa afirmar, em última instância, que o direito ao meio ambiente ecologicamente equilibrado é um direito legal e não fundamental. Essa consideração leva a outra: o Direito Ambiental não passaria de uma especialização do Direito Administrativo, contagiado pela lógica do Estado. Com um agravante, para alguns, um pleonasmo: do Estado e da economia.

\section{REFERÊNCIAS}

BICKENBACH, C. Legislative Margins of Appreciation as the Result of Rational Lawmaking. In: MEßERSCHMIDT, K.; OLIVER-LALANA, A. D. (eds.). Rational lawmaking under review. Nürnberg; Zaragoza: Springer, 2016. p. 235-256.

BRASIL. Supremo Tribunal Federal. Pleno. ADIMC 3540/DF. Rel. Min. Celso de Mello,j. 01/09/2005. Disponível em: http://www.stf.jus.br/portal/ inteiroTeor/obterInteiroTeor.asp?id=387260. Acesso em: 15 mar. 2020.

BRASIL. Supremo Tribunal Federal. 1a. Turma. AI-AgR 794553/RS. Rel. Min. Dias Toffoli, j. 18/06/2013. 
BRASIL. Supremo Tribunal Federal. Pleno. RE 636941/RS. Rel. Min. Luiz Fux, j. 13/02/2014a. Disponível em: http://www.stf.jus.br/portal/inteiroTeor/obterInteiroTeor.asp?idDocumento $=5581480$. Acesso em: 15 mar. 2020.

BRASIL. Supremo Tribunal Federal. Pleno. ADI 4628/DF. Rel. Min. Luiz Fux. j. 17/09/2014b. Disponível em: http://redir.stf.jus.br/paginadorpub/ paginador.jsp?docTP=TP\&docID=7310046. Acesso em: 15 mar. 2020;

BRASIL. Supremo Tribunal Federal. Pleno. $A D C$ 42/DF. Rel. Min. Luiz Fux, julgado em 28/02/2018. Disponível em: http://redir.stf.jus.br/paginadorpub/paginador.jsp?docTP=TP\&docID=750504737. Acesso em: 12 fev. 2020 .

BRASIL. Supremo Tribunal Federal. Pleno. ARE-ED-AgR 1224559/PR. Rel. Min. Dias Toffoli, j. 11/11/2019.

CANOTILHO, J. J. G. Direito Constitucional. Coimbra: Almedina, 1991. CARREÑO, S. M. A. El derecho ambiental entre la cienia, la economía y la sociología: Reflexiones introductorias sobre el valor normativo de los conceptos extrajurídicos. Revista Catalana de Dret Ambiental, v. 10, n. 1, p. 1-26, 2019.

CARVALHO, A. D. Z. Imagens da imparcialidade entre o discurso constitucional e a prática judicial. São Paulo: Almedina, 2020.

COSTA, E. V. Da monarquia à república: momentos decisivos. 6. ed. São Paulo: Unesp, 1999;

COSTA, E. V. Da senzala à colônia. 4. ed. São Paulo: Unesp, 1997.

DUSSEL, E. Direitos humanos e ética da Libertação: pretensão política de justiça e a luta pelo reconhecimento dos novos direitos. Revista InSURgência, Brasília, ano, v. 1, p. 121-135, 2015.

DWORKIN, R. Taking rights seriously. Cambridge: Harvard University Press, 1977.

FARBER, D. A. Is the Supreme Court Irrelevant - reflections on the judicial role in Environmental Law. Minnesota Law Review, v. 81, p. 547, 1996.

GAIO, D. A interpretação do direito de propriedade em face da proteção constitucional do meio ambiente urbano. Curitiba: Renovar, 2015.

GERVIER, P. La limitation des droits fondamentaux constitutionnels par 
l'ordre public. Les Nouveaux Cahiers du Conseil constitutionnel, n. 4, p. 105-112, 2014.

GIBSON, J. L. Challenges to the impartiality of state supreme courts: legitimacy theory and "new-style" judicial campaigns. American Political Science Review, v. 102, n. 1, p. 59-75, 2008.

GRINBERG, K. Em defesa da propriedade: Antônio Pereira Rebouças e a escravidão. Afro-Ásia, Salvador, n. 21-22, p. 111-146, 1998-1999.

GUNKEL, D. J. Robot rights. Cambridge: MIT Press, 2018.

HÄBERLE, P. La Libertad Fundamental en el Estado Constitucional. San Miguel: Pontificia Universidad Católica del Perú, 1997.

HABERMAS, J. Facticidad y Validez: sobre el derecho y el Estado democrático de derecho en términos de teoría del discurso. 4. ed. Madrid: Trotta, 2005.

HASTIE, R.; DAWES, R. M. Rational choice in an uncertain world: the psychology of judgment and decision making. London: Sage, 2009.

IRWIN, J. F.; REAL, D. L. Unconscious influences on judicial decision-making: the illusion of objectivity. McGeorge Law Review, v. 42, p. $1-18,2010$.

KALIL, A. P. M. C.; FERREIRA, H. S. A dimensão socioambiental do Estado de Direito. Veredas do Direito, Belo Horizonte, v. 14, n. 28, p. 329-359, jan./abr. 2017. Disponível em: http://revista.domhelder.edu.br/index. php/veredas/article/view/1010/549. Acesso em: 5 jun. 20.

LAZARUS, R. J. Thirty years of Environmental Protection Law in the Supreme Court. Pace Environmental Law Review, v. 17, p. 1-32, 1999.

MEHLMAN, M. J. Transhumanist dreams and dystopian nightmares: the promise and peril of genetic engineering. Baltimore: The Johns Hopkins University Press, 2012.

MENDES, G. F. Controle de constitucionalidade: hermenêutica constitucional e revisão de fatos e prognoses legislativos pelo órgão judicial. Revista Jurídica da Presidência, Brasília, DF, v. 1, n. 8, 2000. Disponível em: https://revistajuridica.presidencia.gov.br/index.php/saj/ article/viewFile/1063/1047. Acesso em: 11 mar. 2020.

MENDONÇA, J. M. N. Entre a mão e os anéis: a Lei dos Sexagenários e os caminhos da abolição no Brasil. 2. ed. Campinas: Unicamp, 2008. 
NEITZ, M. B. Socioeconomic bias in the Judiciary. Cleveland Stata Law Review, v. 61, p. 137-165, 2013.

NORTON, M. I. et al. Mixed motives and racial bias: the impact of legitimate and illegitimate criteria on decision making. Psychology, Public Policy, and Law, v. 12, n. 1, p. 36-55, 2006.

PAUTZ, M. C. Regulating Greenhouse gas emissions: The Supreme Court, the Environmental Protection Agency, Madison's "Auxiliary Precautions," and Rohr's “Balance Wheel”. Public Integrity, v. 18, n. 2, p. 149-166, 2016.

PRADO, L. R. A. Neutralidade e imparcialidade dos juízes? In: GROENINGA, G. C. (org.). Direito de família e psicanálise: rumo a uma nova epistemologia. Rio de Janeiro: Imago, 2003.

RACHLINSKI, J. J. Processing pleadings and the psychology of prejudgments. DePaul Law Review, v. 60, p. 413-430, 2010.

RENEDO, C. A. La difícil concepción del medio ambiente como derecho constitucional en el ordenamiento español. Revista de Derecho Político, $\mathrm{n}$. 54, p. 129-152, 2002.

RIBEIRO, I. C. Robin Hood versus King John: como os juízes locais decidem casos no Brasil. Brasília, DF: Ipea, 2006.

ROBERTSON, J. Human rights vs. robot rights: forecasts from Japan. Critical Asian Studies, v. 46, n. 4, p. 571-598, 2014.

ROCHA, C. M. O STF e o meio ambiente: a tutela do meio ambiente e sede de controle concentrado de constitucionalidade. Tese (Doutorado) Universidade de São Paulo, São Paulo, 2013. Disponível em: http://www. teses.usp.br/teses/disponiveis/2/2134/tde-05122013-154012/publico/Dissertacao_Final_Caroline_Medeiros_Rocha.pdf. Acesso em: 12 mar. 2020. SAMPAIO, J. A. L. Direitos fundamentais: retórica e historicidade. Belo Horizonte: Del Rey, 2004.

SAMPAIO, J. A. L. Teoria da Constituição e dos direitos fundamentais. Belo Horizonte: Del Rey, 2013.

SAMPAIO, J. A. L. Direitos fundamentais como trufas da maioria. Revista de Estudos Constitucionais, Hermenêutica e Teoria do Direito, São Leopoldo, v. 7, n. 3, p. 226-234, 2015.

SCALCON, R. L. Avaliação de impacto legislativo: a prática europeia e 
suas lições para o Brasil. Revista de Informação Legislativa, Brasília, DF, v. 54, n. 214, p. 113-130, abr./jun. 2017.

STINSON, V. et al. How effective is the motion-to-suppress safeguard? Judges' perceptions of the suggestiveness and fairness of biased lineup procedures. Journal of Applied Psychology, v. 82, n. 2, p. 211-220, 1997.

TANFORD, J. A. The limits of a scientific jurisprudence: The Supreme Court and psychology. Indiana Law Journal, v. 66, p. 137-173, 1990.

TRIBE, L.; DORF, M. Hermenêutica constitucional. Belo Horizonte: Del Rey, 2007

VILANI, R. M. A aplicação do conceito constitucional de desenvolvimento sustentável sob a perspectiva do STJ e do STF. Revista Brasileira de Direito Constitucional, São Paulo, v. 13, n. 1, p. 63-79, 2009.

WEDY, G. O STF e o enfrentamento do conflito aparente entre o princípio da preservação do meio ambiente e o princípio do desenvolvimento econômico e da livre iniciativa. Direito Federal. Revista da Associação dos Juizes Federais do Brasil, Brasília-DF, v. 23, p. 175-202, 2008.

Artigo recebido em: 10/06/2020.

Artigo aceito em: 30/06/2020.

\section{Como citar este artigo (ABNT):}

SAMPAIO, J. A. L.; REZENDE, E. N. Meio ambiente: um direito fundamental de segunda categoria. Veredas do Direito, Belo Horizonte, v. 17, n. 38, p. 273-289, maio/ago. 2020. Disponível em: http://www.domhelder. edu.br/revista/index.php/veredas/article/view/1875. Acesso em: dia mês. ano. 